\title{
Conference Review - The European Association for Terminology, Third Terminology Summit, Brussels - BY: ANNELISE GRINSTED
}

Posted by Michael Lambarena on February 212009 15:22:30

\section{Conference Review}

\section{- The European Association for Terminology, Third Terminology Summit, Brussels}

The European Association for Terminology held its Third Summit in Brussels on the 13th and 14th of November, 2006. It was a special summit due to the fact that it was also the celebration of the 10th anniversary of the European Association for Terminology.

The summit had four Round Tables with a panel of five to six researchers and practitioners on the following themes:

- Theme 1: Terminology Policies and Planning

- Theme 2: Major problems with Minor Languages

- Theme 3: The Terminologist in Profile

- Theme 4: Different Collaborations for Different Needs

The themes are very relevant for a group of researchers and practitioners that have had to manifest themselves over the past decades as a group of professionals with specialized knowledge. When terminology became the specific topic of conferences and seminars in the 1970's and 1980's, the content of these were first and foremost discussions of the theoretical foundations and the subject matters that should be included in terminology work:

- Which theoretical schools could be applied?

- What characterizes terminology - i.e. what are its special traits?

- How could linguistic information be represented?

- How could the new information technology be used, especially to build term banks?

- What was to be taught to future terminologists?

In the 1980's and the 1990's, terminologists went beyond these initial steps to establish a new scientific research area that looked at the environment in which terminology and terminologists formed a 
part. The focus here became terminology as:

- A production factor

- An economic factor

- A distinctive competency, e.g. quality and price

Today, terminology focuses on technological aspects such as language technology, as well as other technologies - and the interface between man and machine.

At the 10th anniversary of the European Association for Terminology, terminologists had a sound forum to discuss aspects of their profession, to reflect on the development of the field, and to project into the future.

The association was founded in October of 1996 and took the POINTER Final Report from 1995 as a point-of-departure in which, "a broad-based professional mem-bership organiza-tion for facilitating fu-ture activities, an anchor for special interest groups on specific problems and topics, and a vehicle for promoting the profession and aware-ness of it" was proposed. POINTER which stands for Proposals for an Operational Infrastructure for Terminology in Europe was a project co-funded by the European Commission and DG XIII-E as part of its Multilingual Action Plan (MLAP), to create a set of concrete recommendations for activities leading to a coordinated but flexible terminology infrastructure for Europe.

The birth of the association in 1996 was not an easy one. There were both many individual positions and collective concerns, even though a number of stakeholders in the field of terminology had contributed input to the POINTER report. However, these concerns had to be overcome in the first years of the association's life.

Therefore, it was a great pleasure to see a very large number of participants and new members from all over the world. Not only were there representatives from many of the new European countries, but there were also participants from Canada, Africa, the Middle East, etc. The word "European", as used in the title of the association does not exclude any nationality from membership.

Congratulations to the Board of the EAFT and the organizers from the Institute Libre Maria Haps for a well organized and relevant conference! 


\section{Author}

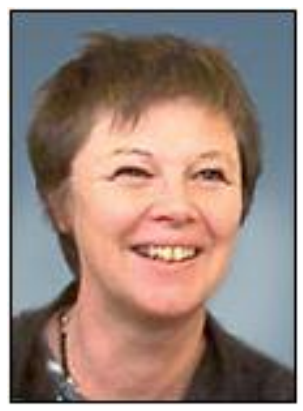

Annelise Grinsted, Ph.D., Associate Professor at Institute of Business Communication and Information Science, The University of Southern Denmark, was one of the founders and the first president of the European Association for Terminology.

This article was uploaded to http://www.languageatwork.eu in July of 2009 and published under a "Creative Commons license Attribution Non-commercial (by-nc)" for more information please go to: http://creativecommons.org/about/license/ 